\title{
DIREITOS FUNDAMENTAIS: RESTRIÇÕES E COLISÕES
}

\section{FUNDAMENTAL RIGHTS: RESTRICTIONS AND COLLISIONS}

\author{
Alessandro Otavio Yokohama ${ }^{1}$ \\ Celso Hiroshi Iocohama ${ }^{2}$
}

\section{RESUMO}

O presente trabalho expõe as diferentes formas de conformação e restrição aos direitos fundamentais, além de abordar o fenômeno da colisão entre tais valores, objetivados em normas do tipo princípio. A distinção entre fenômenos jurídicos díspares é o berço de uma dogmática precisa, sendo esse o móvel e a justificativa da distinção entre conformações, restrições e as subespécies desta última. Levado a cabo essa tarefa, muito mais adequada se mostrará as técnicas para solução das colisões entre direitos fundamentais, sejam elas a ponderação, a razoabilidade ou a proporcionalidade.

Palavras-chave: colisão; direitos fundamentais; razoabilidade; proporcionalidade.

\begin{abstract}
The present work exposes the different forms of conformation and restriction of fundamental rights, in addition to addressing the phenomenon of collision between such values, aimed at principles of the type principle. The distinction between disparate legal phenomena is the cradle of precise dogmatics, which is the motive and the justification for the distinction between conformations, restrictions and the subspecies of the latter. Having carried out this task, the techniques for solving the collisions between fundamental rights will be much more appropriate, be they weighting, reasonableness or proportionality.
\end{abstract}

Keywords: collision; fundamental rights; reasonableness; proportionality.

SUMÁRIO: Introdução; 1 Restrições e conformações de direitos fundamentais; 2 Restrições de direitos fundamentais; 3 Restrições legislativas; 4 Restrições nãolegislativas; 5 Colisões de direitos fundamentais; Conclusões; Referências.

\section{INTRODUÇÃO}

1 Advogado. Mestre em Teoria do Direito e do Estado pela Universidade Federal de Santa Catarina (UFSC, Florianópolis/SC, Brasil). Doutor em Filosofia do Direito e do Estado pela Pontifícia Universidade Católica de São Paulo (PUC-SP, São Paulo/SP, Brasil). Professor da Graduação em Direito e do Mestrado em Direito Processual Civil da Universidade Paranaense (UNIPAR, Umuarama/PR, Brasil). E-mail: aoyokohama@uol.com.br.

2 Advogado. Mestre em Direito pela Universidade Estadual de Londrina (UEL, Londrina/PR, Brasil). Doutor em Educação pela Universidade de São Paulo (USP, São Paulo/SP, Brasil). Professor da Graduação em Direito e do Mestrado em Direito Processual Civil da Universidade Paranaense (UNIPAR, Umuarama/PR, Brasil).E-mail: iocohama@uol.com.br. 
De um modo geral, não há mais celeuma sobre a natureza principiológica das normas $^{3}$ garantidoras dos direitos fundamentais.

Afastada a regra como suporte jurídico de tais direitos, abre-se o problema da "precedência condicionada" dos princípios, já que, como mandados de otimização, os casos em que se vê colisão entre valores igualmente protegidos são resolvidos pela técnica da ponderação.

Todavia, antes mesmo de se aprofundar o estudioso no campo da "razoabilidade", "proporcionalidade" e mesmo "ponderação", é mister que esteja bem estabelecido o significado de "restrições" de direitos fundamentais, bem como delineadas as situações em que, verdadeiramente, ocorrem "colisões" entre tais princípios.

É dentro desse recorte ao assunto, por si só um oceano de problemas, teóricos e práticos, é que se propõe a exposição que segue.

\section{RESTRIÇÕES E CONFORMAÇÕES DE DIREITOS FUNDAMENTAIS}

Em linhas gerais, é partindo do conceito dos direitos à prestação normativa que chegamos às normas restritivas e conformadoras de direitos fundamentais.

"Restrições" aqui, afastam-se das "conformações" ou "configurações" de direitos fundamentais conforme reconhece farta doutrina ${ }^{4}$.

\footnotetext{
3 Que as normas sejam o gênero dos quais as regras e os princípios representam espécies já é algo uniforme na doutrina. Exemplos extraído de YOKOHAMA, Alessandro Otavio. Teoria da proporcionalidade: o Judiciário como legislador. Porto: Editorial Juruá, 2018, p. 32: Dworkin, Ronald. Levando os Direitos a sério. São Paulo: Martins Fontes, 2002, p. 39 e s.; CANOTILHO, José Joaquim Gomes. Direito constitucional e teoria da Constituição. 2 ed., Coimbra: Almedina, 1998, p. 1036 e s.; ALEXY, Robert. Teoría de los derechos fundamentales. Madrid: Centro de Estudios Constitucionales, 2002, p. 81 e s.; ESPÍNDOLA, Ruy Samuel. Conceito de princípios constitucionais. 2 ed., São Paulo: RT, 2002, p. 66 e s.; GRAU, Eros Roberto. A ordem econômica na Constituição de 1988. 4 ed., São Paulo: Malheiros, 1998, p. 73 e s.; HECK, Luís Afonso. Regras, Princípios Jurídicos e sua estrutura no pensamento de Robert Alexy. In: Leite, George Salomão (org.). Dos princípios constitucionais: considerações em torno das normas principiológicas da Constituição. São Paulo: Malheiros, 2003, p. 65 e s.; ÁVILA, Humberto. Teoria dos princípios. $3^{a}$ ed., São Paulo: Malheiros, 2003, p. 55 e s.; DANTAS, David Diniz. Interpretação constitucional no pós-positivismo. São Paulo: Madras, 2004, p. 62 e s.; MENDES, Gilmar Ferreira; COELHO, Inocêncio Mártires; BRANCO, Paulo Gustavo Gonet. Hermenêutica constitucional e direitos fundamentais. Brasília: Brasília Jurídica, 2002, p. 44 e s.; BONAVIDES, Paulo. Curso de direito constitucional. 13ª ed., São Paulo: Malheiros, 2003, p. 277 e s.; GUERRA FILHO, Willis Santiago. Teoria da ciência jurídica. São Paulo: Saraiva, 2001, p. 126 e s.; normativa. Revista de Processo, n. 80, São Paulo: RT, 1995, p. 202 e s.

4 No Brasil: MENDES, Gilmar Ferreira. Direitos fundamentais e controle de constitucionalidade. 3 ed. São Paulo: Saraiva, 2004, p. 15 e s.; MENDES, Gilmar Ferreira; COELHO, Inocêncio Mártires; BRANCO, Paulo Gustavo Gonet. Hermenêutica constitucional e direitos fundamentais. Brasília: Brasília Jurídica, 2002, p. 213 e s.; STEINMETZ, Wilson Antônio. Colisão de direitos fundamentais e princípio da proporcionalidade. Porto Alegre: Livraria do Advogado, 2001, p. 39-42. Na Alemanha: ALEXY, Robert. Teoría de los derechos fundamentales. Madri: Centro de Estudios Constitucionales, 2002, p. 321-329; HÄBERLE, Peter. La garantia del contenido esencial de los derechos fundamentales. Madrid: Dykinson, 2003, p. 69-75; HESSE, Konrad. Elementos de direito constitucional da República Federal da Alemanha. Porto Alegre: Sérgio Antônio Fabris Editor, 1998, p. 247-248. Em Portugal: CANOTILHO, José Joaquim Gomes. Direito constitucional e teoria da Constituição. 7 ed. Coimbra: Almedina, 2003, p. 1.263-1.264; QUEIROZ, Cristina M. M. Direitos fundamentais (teoria geral). Coimbra: Coimbra Editora, 2002, p. 199202; ANDRADE, José Carlos Vieira de. Os direitos fundamentais na Constituição portuguesa de 1976. 4 ed. Coimbra: Almedina, 2004, p. 291-292; MIRANDA, Jorge. Manual de Direito Constitucional. Toma IV, 2 ed. Coimbra: Coimbra Editora, 1997, p. 278; NOVAIS, Jorge Reis. As restrições aos direitos fundamentais não expressamente autorizados pela Constituição. Coimbra: Coimbra Editora, 2003, p. 182.
} 
Tanto a ideia de restrição quanto a ideia de conformação nascem a partir daquelas tarefas de legislação impostas pela Constituição para tornarem eficazes os direitos fundamentais, já que se encontram em uma situação de carência de organização jurídica quanto as condições reais de vida que devem incidir ${ }^{5}$.

A ideia de restrição de direito fundamental está diretamente ligada à restrição ou limitação prima facie do domínio de proteção desses direitos ${ }^{6}$. Só nascem a partir de autorização expressa da Constituição ${ }^{7}$, usando de expressões como "nos termos da lei", "nas hipóteses e na forma que a lei estabelecer", "salvo nas hipóteses previstas em lei" etc. ${ }^{8}$

Já as hipóteses em que a Constituição pressupõe conformação de certo direito fundamental, o papel atribuído à legislação infraconstitucional é de regular ${ }^{9}, \operatorname{precisar}^{10}$, densificar $^{11}$, configurar - que engloba a regulamentação e a concretização ${ }^{12}$, , o direito em questão. Atua-se, nesses casos, como aqueles conceitos jurídicos indeterminados.

A partir desse processo tipicamente legislativo, os titulares passam a exercer efetivamente seus direitos. ${ }^{13}$

$\mathrm{Na}$ Constituição brasileira, a legislação ordinária veio conformar, por exemplo, o direito de propriedade material e intelectual (art. $5^{\circ}$, XXII a XXVII), o direito das sucessões (art. $5^{\circ}, \mathrm{XXX}$ e XXXI), o direito à proteção do consumidor (art. $5^{\circ}, \mathrm{XXXII),o}$ direito à efetiva e célere proteção judiciária em geral (art. $5^{\circ}, \mathrm{XXXV}, \mathrm{LXXIV}$ e LXXVIII) e em específico (art. 5, LXVIII a LXXIII).

O mesmo pode ser dito na Alemanha quanto ao direito de propriedade, conforme ensina PETER HÄBERLE, afirmando que o Tribunal Federal Alemão fala em uma conformação legislativa concreta da vinculação social da propriedade imóvel. Nesse caso, o TFA nunca "limita" ou "restringe" o direito à propriedade, mas sim concretiza limites conforme sua essência ${ }^{14}$.

Como se vê, os direitos fundamentais estão sujeitos a duas espécies normativas totalmente distintas: as normas conformadas e as normas restritivas.

Embora a análise do princípio da proporcionalidade esteja presente em ambas as categorias, os maiores abusos do Poder Público são constatados nas restrições de direitos fundamentais, que, como visto, atingem negativamente o conteúdo material desses direitos.

E é sobre as restrições que passamos a tratar.

\section{RESTRIÇÕES DE DIREITOS FUNDAMENTAIS}

Na Espanha: CAMAZANO, Joaquim Brage. Los limites a los derechos fundamentales. Madri: Dykinson, 2004, p. 69-75; PULIDO, Carlos Bernal. El principio de proporcionalidad y los derechos fundamentales. 2 ed. Madri: Centro de Estudios Políticos y Constitucionales, 2005, p. 683-687.

${ }^{5}$ HESSE, Konrad. Op. cit., p. 247.

${ }^{6}$ GOMES CANOTILHO, José Joaquim. Op. cit., p. 1.263

${ }^{7}$ ANDRADE, José Carlos Vieira de. Op. cit., p. 290.

${ }^{8}$ MENDES, Gilmar Ferreira. Op. cit., p. 15.

${ }^{9}$ ALEXY, Robert. Op. cit., p. 322.

${ }^{10}$ GOMES CANOTILHO, José Joaquim. Op. cit., p. 1.263.

${ }^{11}$ MENDES, Gilmar Ferreira. Op. cit., p. 16.

12 QUEIROZ, Cristina M. M. Op. cit., p. 201.

${ }^{13}$ NOVAIS, Jorge Reis. Op. cit., p. 182.

${ }^{14}$ HÄBERLE, Peter. Op. cit., p. 130. 
As restrições dos direitos fundamentais são concebidas a partir da estrutura das normas/princípios que os resguardam, com base sempre na Constituição ${ }^{15}$. O conteúdo aberto e flexível dessas normas permite que o Estado as invada, limitando sua aplicação em conformidade com a necessidade de convivência harmoniosa dos mais variados valores presentes em uma sociedade pluralista/inclusiva.

É nesse contexto que JORGE MIRANDA aponta como razões de quase todas as restrições: (i) a conjugação dos direitos, liberdades e garantias entre si e com outros direitos fundamentais, pressupondo uma situação de conflito de direito; e (ii) a mesma conjugação com princípios objetivos, institutos, interesses ou valores constitucionais de outra natureza, fadadas em uma relação especial de poder $^{16}$.

A partir daí, já se pode aferir o princípio da proporcionalidade ao lado dessas diversas situações de tensão e entre as mais variadas facetas dos direitos fundamentais, justificadas, boa parte das vezes, pelo próprio interesse público em contrapartida às garantias individuais dos cidadãos.

Exemplo disso pode ser observado a partir da dicção do art. $5^{\circ}$, XXXIII, da CF/88, em que se garante o direito fundamental de receber dos órgãos públicos informações de interesse particular, salvo aquelas cujo sigilo seja imprescindível à segurança da sociedade e do Estado. Trata-se de típica restrição a um interesse particular nascida a partir de imperativo justificado pelo interesse público.

A situação pode ser invertida: às vezes o interesse público fica de lado para a proteção de um único valor individual.

É o caso, por exemplo, quando se obtém uma ordem judicial para que o Estado pague um tratamento médico em outra país para uma pessoa necessitada. Trata-se de típica situação em que o interesse de uma única pessoa se sobrepõe ao interesse público manifestado no desfalque, ainda que justificável, do orçamento público adrede preparado.

Essa análise superficial serve apenas para demonstrar que o que está em jogo nas restrições de direitos fundamentais é o conteúdo material garantido pelo texto constitucional, ou melhor, ao denominado núcleo essencial dos direitos fundamentais ${ }^{17}$.

A origem desse núcleo é ligada à história constitucional de Weimar, consagrandose definitivamente com a Constituição de Bonn ${ }^{18}$. Hoje, além da Constituição alemã, a

\footnotetext{
${ }^{15}$ HESSE, Konrad. Op. cit., p. 250

${ }^{16}$ MIRANDA, Jorge. Manual de Direito Constitucional. Tomo IV. 2 ed. Coimbra: Coimbra Editora, 1998, p. 301.

${ }^{17}$ Sobre o tema, v. SANCHIS, Luis Prieto. Justicia constitucional y derechos fundamentales. Madri: Editorial Trotta, 2003, p. 230-241.

18 "Pretendendo assumir as lições do período anterior, a consagração da garantia do núcleo essencial surge, diferentemente, na Lei Fundamental de Bonn, ligada a esse esforça de atribuição de um sentido constitucional efetivo aos direitos fundamentais, que se refletiria, igualmente, como temos visto, num conjunto de outros institutos e doutrinas, desde os limites aos limites propriamente ditos e o acesso direto ao Tribunal Constitucional para defesa dos direitos fundamentais até aos princípios e regras da vinculação de todas as entidades públicas, da sua aplicabilidade imediata, do seu efeito de irradiação, da teoria do efeito recíproco, da Drittwirkung ou da associação dos direitos fundamentais ao princípio da dignidade da pessoa humana e ao direito natural enquanto impedimentos à sua eventual afetação em processo de revisão constitucional" (NOVAIS, Jorge Reis. As restrições aos direitos fundamentais não expressamente autorizadas pela Constituição. Coimbra: Coimbra Editora, 2003, p. 779). No Brasil, sob o processo de revisão constitucional e a situação dos direitos fundamentais, encarados como cláusulas pétreas, conferir STRECK, Lênio Luiz. Constituição: limites e perspectivas de revisão. 2 ed. Porto Alegre: Rigel, 1993, p. 27 e s.
} 
Constituição portuguesa $\left(\operatorname{art.} 18^{\circ}, \text { n. } 3\right)^{19}$ e a Constituição espanhola (art. 53, n. 1) $)^{20}$ trazem essa garantia inatingível de cada direito fundamental.

$\mathrm{Na}$ atualidade, foram desenvolvidas algumas teorias justificadoras do verdadeiro conteúdo desse núcleo. ${ }^{21}$

A primeira teoria é chamada de teoria absoluta. Segunda ela, o núcleo essencial dos direitos fundamentais é uma unidade autônoma independente localizada em cada direito em si mesmo considerado, independentemente da situação concreta envolvida, permanecendo, portanto, intocável em qualquer situação.

A segunda é a teoria relativa que se livra desse aspecto de total independência ocupando uma posição mais maleável. Nesse caso, o núcleo essencial de um direito fundamental não é predeterminado e absoluto, mas sim apurável apenas a partir de uma situação concreta.

Além dessas duas, há ainda uma teoria que veio unir ambas as vertentes se fundando principalmente no princípio da proporcionalidade. Segunda essa teoria mista, admite-se, além de um núcleo absoluto (teoria absoluta), eventual limitação do conteúdo dos direitos fundamentais (teoria relativa), o que acaba por forma, como é intuitivo, uma teoria mista.

Sobre essa última teoria, KONRAD HESSE assenta que:

Na discussão sobre a interpretação indicada no artigo 19, alínea 2, da Lei Fundamental, é sustentada tanto a concepção, que a restrição proíbe limitações desproporcionais como esta, que a determinação subtrai o "núcleo essencial absoluto" dos direitos fundamentais da disposição do legislador. A partir do ponto de vista aqui defendido, a proibição de limitações desproporcionais efetua também uma proteção absoluta do 'núcleo essencial' dos direitos fundamentais, naturalmente, sob o pressuposto, que proporcionalidade seja entendida não só no sentido de uma perseguição de uma finalidade econômica, mas que a admissibilidade de tal perseguição de uma finalidade, exatamente, também seja aferida ao direito fundamental a ser limitado. Desse modo, são evitadas as debilidades de

\footnotetext{
19 "A lei só pode restringir direitos, liberdades e garantias nos casos expressamente previstos na Constituição, devendo as restrições limitar-se ao necessário para salvaguardar outros direitos e/ou interesses constitucionalmente protegidos."

20 "Os direitos e liberdades reconhecidos no Capítulo segundo do presente Título vinculam a todos os poderes públicos. Só por lei, que em todos os casos deverá respeitar seu conteúdo essencial, poderá regularse o exercício de tais direitos e liberdades, que se tutelaram de acordo com o previsto no art. 161, 1, 'a'.” ${ }^{21}$ Sobre essas teorias, de um modo geral, v. MENDES, Gilmar Ferreira. COELHO, Inocêncio Mártires. BRANCO, Paulo Gustavo Gonet. Hermenêutica constitucional e direitos fundamentais. Brasília: Brasília Jurídica, 2002, p. 243-244; MIRANDA, Jorge. Manual de Direito Constitucional. Tomo IV. 2 ed. Coimbra: Coimbra Editora, 1998, p. 307-308; NOVAIS, Jorge Reis. Op. cit. p. 782; VIEIRA DE ANDRADE, José Carlos. Os direitos fundamentais na Constituição portuguesa de 1976. 3 ed. Coimbra: Almedina, 2004, p. 303 e s.; BIAGI, Cláudia Perotto. A garantia do conteúdo essencial dos direitos fundamentais na jurisprudência constitucional brasileira. Porto Alegre: Sérgio Fabris Editor, 2005, p. 80; BARROS, Suzana de Toledo. $O$ princípio da proporcionalidade e as normas restritivas de direitos fundamentais. 3 ed. Brasília: Brasília Jurídica, 2003, p. 101; QUEIROZ, Cristina M. M. Direitos fundamentais (teoria geral). Coimbra: Coimbra Editora, 2002, p. 212.
} 
ambas as concepções, ou seja, por um lado, uma relativização do artigo 19, alínea 2, da Lei Fundamental, por outro, o abandono dos direitos fundamentais, que estão sob reserva legal, à disposição discricional do legislador, que só deve violar o "núcleo essencial absoluto" a ser determinado não facilmente.

Nesse mesmo sentido, PETER HÄBERLE destaca que os limites admissíveis aos direitos fundamentais devem ser determinados por meio da ponderação de bens orientada pelo sistema objetiva de valores da Constituição, além de só ser admitidos limites conforme a essência desses direitos fundamentais manifestados, portanto, em um núcleo absoluto $^{22}$.

O que importa frisar é que qualquer restrição que invada essa garantia essencial de cada direito fundamental será considerada inconstitucional.

\section{RESTRIÇÕES LEGISLATIVAS}

Um outro ponto importante é a relação entre a aplicação/eficácia dos direitos fundamentais e as restrições emanadas do Poder Legislativo. Nesse ponto, chega-se a uma das facetas do princípio da legalidade: a chamada reserva legal.

Essa relação é tratada também por PETER HÄBERLE com uma ênfase quase exagerada, quando atribui às normas restritivas de direitos fundamentais a função mediadora da Constituição em relação à realidade social, ocupando a função de atualizar suas normas, conferindo-lhes vigência real ${ }^{23}$.

Segundo HÄBERLE, "se faltasse aos direitos fundamentais o subnível do ordenamento jurídico que está hierarquicamente por debaixo da Constituição, quedariam sem eficácia, figurariam "só no papel". E mais: "a Constituição se transformar na 'Constituição' no pleno sentido da palavra por meio da atividade do legislador de conformação e de limitação dos direitos fundamentais". ${ }^{24}$

Ao que parece, nesse ponto, HÄBERLE incorre em exagero ao menos em alguns pontos.

É certo que as normas restritivas e conformadoras de direitos fundamentais ocupam lugar de crucial importância e demandam aplicação correta e em conformidade com o todo o sistema jurídico. Mas, daí a situar tais direitos numa posição de dependência, há uma grande distância e muito que se questionar.

No contexto político-institucional democrático essa relação de vinculação é totalmente equivocada, aproximando-se do que CARL SCHMITT pregava sob a égide do Estado de Weimar, conhecido como Império da Lei.

\footnotetext{
${ }^{22}$ HÄBERLE, Peter. Elementos de direito constitucional da República Federal da Alemanha. Porto Alegre: Sérgio Antônio Fabris Editor, 1998, p. 267-268.

${ }^{23}$ HÄBERLE, Peter. Op. cit., p. 172.

${ }^{24}$ HÄBERLE, Peter. Op. cit., p. 171. No mesmo sentido, v. BIAGI, Cláudia Perotto. A garantia do conteúdo essencial dos direitos fundamentais na jurisprudência constitucional brasileira. Porto Alegre: Sérgio Antônio Fabris Editor, 2005, p. 56-59.
} 
As palavras de SCHMITT, nesse ponto, são de suma importância sob um ponto de vista comparativo: "por isso [os direitos fundamentais] não podem ter lugar senão a base de leis, entendendo-se Lei no conceito próprio do Estado de Direito, como uma norma geral e não como qualquer ato particular do Rei ou do Corpo Legislativo, realizado em forma de lei. O direito fundamental e a liberdade se encontram, pois, abaixo da salvaguarda da Lei. A proteção consiste no que a Lei, no sentido do Estado de Direito, necessita ter certas propriedades objetivas, com que se satisfaz à ideia do princípio da distribuição". ${ }^{25}$

De plano, percebemos que ambas as opiniões caminham principalmente contra uma das características primordiais contemporâneas desses direitos: sua aplicabilidade imediata. Além disso, já é cediço a necessária força normativa atribuída às normas constitucionais, conforme vem defendendo assiduamente KONRAD HESSE ${ }^{26}$.

Afasta-se, com base nesses dois argumentos, a validade dessa tendência à legalidade relatada por LÊNIO STRECK em alentada obra ${ }^{27}$.

O ponto inicial para se chegar às espécies de restrições dos direitos fundamentais em si, parte da análise de algumas teorias tradicionalmente consagradas dentre os que lidam com esse tema.

A primeira delas é conhecida como teoria externa. O ponto inicial para quem defende essa teoria é o dualismo conceitual obtido entre o conceito do direito individual em si e a restrição que o acomete. A restrição é criada através de uma necessidade externa ao direito, como forma de compatibilizar os direitos individuais contrapostos dos outros indivíduos e dos bens coletivos, originando, daí, um direito restringido. ${ }^{28}$

Nesse caso, quando a Constituição consagra os direitos fundamentais, delimita seu âmbito de proteção e, por outro lado, o coloca condicionalmente à disposição dos poderes centrados nas cláusulas de reserva, desde que observem os requisitos constitucionais exigidos. É dessa conjunção entre âmbito de proteção e possibilidade constitucionalmente reconhecida de restrição que resulta, ao final, um âmbito constitucional de garantia efetiva e imune a qualquer outra restrição. ${ }^{29}$

Ao contrário da teoria externa, temos a teoria interna, defendida principalmente por PETER HÄBERLE ${ }^{30}$. Segunda essa corrente, os direitos individuais e suas restrições são definidos e unidos em um único ato, originando o direito com um determinado conteúdo. A ideia de restrição sai de cena para que se chegue ao limite do direito fundamental.

\footnotetext{
${ }^{25}$ SCHMITT, Carl. Teoría de la Constitución. Madri: Alianza, 1996, p. 180.

${ }^{26}$ HESSE, Konrad. A força normativa da Constituição. Porto Alegre: Sérgio Antônio Fabris Editor, 1991, p. 22-23.

27 "Há, no Estado moderno - como no Brasil - uma supremacia da lei diante da tendência crescente de codificar o Direito para atender a uma exigência de maior certeza e segurança para as relações, devido à possibilidade de maior certeza e segurança para as relações, devido à possibilidade de maior rapidez na elaboração e modificação do Direito legislado. Daí que o costume passa a ser fonte do Direito somente quando incorporado na lei escrita". (STRECK, Lênio Luiz. Súmulas no direito brasileiro: eficácia, poder e função - A ilegitimidade constitucional do efeito vinculante. 2 ed. Porto Alegre: Livraria do Advogado, 1998, p. 75).

${ }^{28}$ ALEXY, Robert. Teoría de los Derechos Fundamentales. Madri: Centro de Estudios Constitucionales, 2002, p. 268.

${ }^{29}$ NOVAIS, Jorge Novais. Op. cit., p. 299-300.

${ }^{30}$ HÄBERLE, Peter. Op. cit., p. 167.
} 
Qualquer dúvida acerca das restrições dos direitos fundamentais seriam acerca de qual o conteúdo do direito em tela ${ }^{31}$, apurado excepcionalmente através de um processo de interpretação/aplicação do Direito ${ }^{32}$.

Como ensina JORGE REIS NOVAIS, aqui os limites não são elementos externos legitimadores das intervenções abatidas do conteúdo dos direitos fundamentais, mas sim concretizações de sua substância jurídica, ou seja, "fronteiras do seu âmbito de garantia constitucional, reveladas a partir de dentro do direito" 33 .

Isso tudo levou ROBERT ALEXY ${ }^{34}$ a fixar quais os parâmetros de escolha a serem seguidos pelo intérprete para adoção de cada teoria. Tais hipóteses estão diretamente ligadas à concepção que se tem sobre os direitos individuais. Se considerados posições definitivas (regras), deve-se adotar a teoria externa; se considerados valores prima facie (princípios), o ideal é que se adote a teoria interna.

Partindo de tudo isso, o próximo passo é sistematizar as espécies de restrições, ressaltando já de plano que podem vir da própria Constituição (restrições imediatas), ou esta pode autorizar uma lei infraconstitucional que restrinja determinado direito (restrições mediatas). ${ }^{35}$

Exemplos de restrições imediatas na Constituição brasileira de 1988 não faltam. Usar da completude nesse passo seria extremo exagero que levaria à inutilidade. Por isso, destacamos apenas algumas.

$\mathrm{O}$ art. $5^{\circ}, \mathrm{XI}$, garante aos cidadãos brasileiros a inviolabilidade da residência "salvo em caso de flagrante delito ou desastre, ou para prestar socorro, ou, durante o dia, por determinação judicial". Trata-se de típica restrição de direito fundamental inviolabilidade de residência - em que a própria Constituição cuidou de fixar a restrição.

No mesmo sentido, o art. $5^{\circ}$, XVI, consagra a todos o direito de reunião, desde que a mesma seja pacífica e realizada sempre sem armas.

Nas restrições mediatas ou restrições legais, a Constituição autoriza o legislador a efetivá-las, usando de expressões como "na forma da lei", "nos termos da lei" etc. É o caso, por exemplo, dos incisos VI ${ }^{36}, \mathrm{VII}^{37}$ e XV ${ }^{38}$ do art. $5^{\circ}$ da Constituição de 1988.

Essas últimas, de seu turno, são divididas em reserva legal simples e reserva legal qualificada.

São reservas legais qualificadas aqueles casos em que a Constituição não se limite a clamar por intervenção legislativa como garantia de determinado direito, ditando, ainda, as condições especiais e os fins a serem seguidos pelo legislador, como, por exemplo, o

\footnotetext{
${ }^{31}$ ALEXY, Robert. Op. cit., p. 268-269.

${ }^{32}$ Nesse sentido, CAMAZANO afirma que "o processo de aplicação do Direito tem a tarefa de examinar o conteúdo aparente do Direito, para determinar se representa o verdadeiro conteúdo do mesmo" (CAMAZONO, Joaquim Brage. Op. cit., p. 140).

${ }^{33}$ NOVAIS, Jorge Reis. Op. cit., p. 313.

${ }^{34}$ ALEXY, Robert. Op. cit., p. 269.

${ }^{35}$ ALEXY, Robert. Op. cit., p. 277. CANOTILHO, José Joaquim Gomes. Op. cit., p. 1.277. QUEIROZ, Cristina M. M. Op. cit., p. 203 e s.

${ }^{36}$ VI - é inviolável a liberdade de consciência e de crença, sendo assegurado o livre exercício dos cultos religiosos e garantida, na forma da lei, a proteção aos locais de culto e a suas liturgias;

${ }^{37}$ VII - é assegurada, nos termos da lei, a prestação de assistência religiosa nas entidades civis ou militares de internação coletiva;

${ }^{38} \mathbf{X V}$ - é livre a locomoção no território nacional em tempos de paz, podendo qualquer pessoa, nos termos da lei, nele entrar, permanecer ou dele sair com os seus bens;
} 
art. $5^{\circ}$, XIII $^{39}$, da Constituição brasileira de 1988. Já a reserva legal simples é aquela que se limita em determinar que o legislador regulamente o direito em questão, deixando-o livre de quaisquer imperativos específicos sobre a matéria regulamentada, como no exemplo já citado do inciso VI do art. $5^{\circ}$ de nossa Constituição atual.

Registra-se que a discricionariedade atribuída ao legislador nas reservas legais simples deve ser encarada com certas restrições, sob pena de se ver esvaziado consideravelmente o conteúdo dos direitos fundamentais. O exame o princípio da proporcionalidade, neste ponto, é de crucial importância.

\section{RESTRIÇÕES NÃO-LEGISLATIVAS}

Saindo das reservas legais, há ainda outra espécie de restrição de direitos fundamentais não incluída necessariamente na atuação do legislador.

No caso, parte-se do raciocínio de que ao lado de um determinado direito fundamental, ainda que não submetido a qualquer restrição legislativa, haverá um outro direito em contrapartida também garantido pelo constituinte, originando, sob o ponto de vista dogmático, os chamados limites imanentes dos direitos fundamentais. ${ }^{40}$

Tais limites são legitimados a partir do próprio caráter principiológico prima facie das normas de direitos fundamentais, nascidos a partir da concepção da teoria interna das restrições.

Essa situação é bem elucidada pelo já citado JORGE REIS NOVAIS ${ }^{41}$, referência obrigatória sobre o tema, tratando da consagração inicial dos limites imanentes:

A categoria dos limites imanentes dos direitos fundamentais, enquanto limites não escritos e residentes $a b$ initio no interior do direito fundamental e delimitando as fronteiras do seu conteúdo juridicamente relevante, constituía-se, assim - juntamente com uma certa concepção restritiva da previsão normativa, em associação com ela ou integrando-a enquanto uma das suas modalidades -, como elemento nuclear da concepção de direitos fundamentais na teoria interna. Sendo todos os direitos fundamentais imanentemente limitados, não apenas pela sua qualidade jurídica - e daí a exclusão da proteção liminarmente derivada da interpretação da respectiva previsão normativa -, mas também pela sua necessária compatibilização originária com os outros valores igualmente dignos de proteção constitucional, tudo o que exigiria, no plano da atuação dos poderes constituídos nos direitos fundamentais

\footnotetext{
39 XIII - é livre o exercício de qualquer trabalho, ofício ou profissão, atendidas as qualificações profissionais que a lei estabelecer;

${ }^{40}$ A expressão "limites imanentes" foi difundida universalmente e tem aceitação ímpar em todo o mundo. Mesmo reconhecendo tal fato, JOAQUÍN BRAGE CAMAZANO sugere que o termo mais apropriado para caracterizar essa categoria de limitações aos direitos fundamentais seria "limites implícitos", isto é, "limites que não estão expressos ou literalmente previstos para um determinado direito fundamental, porém, da aplicação de uma interpretação conjunta do texto constitucional, se deduzem tais limites implicitamente" (CAMAZANO, Joaquín Brage. Op. cit., p. 164).

${ }^{41}$ NOVAIS, Jorge Reis. Op. cit., p. 438.
} 
sem reservas seria ou mera explicitação concretização, interpretação e revelação desses limites imanentes ou, em alternativa, violação do conteúdo constitucional dos direitos fundamentais.

Em sua essência, os limites imanentes dos direitos fundamentais nascem a partir da interpretação adjacente do texto constitucional, da qual é inegável o fato de que se devem consolidar sistematicamente todos os valores ali resguardados.

Nas palavras de JOSÉ CARLOS VIEIRA DE ANDRADE, os limites imanentes constituem as fronteiras definidas pela própria Constituição que os cria ou recria. ${ }^{42}$

Ao tratar desses limites, CANOTILHO ressalta que nascem a partir do resultado da ponderação de princípios constitucionais, conducente ao afastamento definitivo do caráter prima facie de um princípio perante um caso concreto. ${ }^{43}$

Da mesma forma, HÄBERLE ${ }^{44}$ constata que é a partir de um processo de ponderação de bens que se chega aos limites gerais admissíveis aos direitos fundamentais e, em específico, aos limites imanentes:

Para a determinação dos limites imanentes necessita-se da ponderação de bens - e esta exige sensibilidade para o equilíbrio, com o que tem que ver o Direito Constitucional -, uma ponderação de bens com relação a qual se toma em conta o postulado da significação dos direitos fundamentais para a vida em seu conjunto, como o caráter de regra ou de princípio constitucional de tais direitos.

Exemplo desse tipo de restrição pode ser obtido pela análise sistemática do art. $5^{\circ}, \mathrm{IX}, \mathrm{da} \mathrm{CF} / 88$, e o princípio da dignidade da pessoa humana (art. $1^{\circ}$, III).

O primeiro deles garante a livre expressão da atividade intelectual, artística, científica e de comunicação, independentemente de censura ou licença. A pergunta que se faz é se seria livre a publicação de um jornal ou periódico cujo título e conteúdo teriam como objeto ideias explicitamente racistas. E a resposta, certamente, será negativa. Nesse caso, a liberdade de expressão é restringida como forma de garantir a dignidade humana das pessoas atingidas com referida publicação, fixando, assim, limites ao seu exercício.

\section{COLISÕES DE DIREITOS FUNDAMENTAIS}

Vê-se claramente que a análise dos limites imanentes leva a outra situação costumeiramente tratada na teoria dos direitos fundamentais: a colisão entre esses direitos. ${ }^{45}$

\footnotetext{
${ }^{42}$ ANDRADE, José Carlos Vieira de. Op. cit., p. 292.

${ }^{43}$ CANOTILHO, José Joaquim Gomes. Op. cit., p. 1.282.

${ }^{44}$ HÄBERLE, Peter. Op. cit., p. 54.

45 Sobre o tema, v. CLÈVE, Clémerson Merlin. FREIRE, Alexandre Reis Siqueira. Algumas notas sobre colisão de direitos fundamentais. In: GRAU, Eros Roberto. CUNHA, Sérgio Sérvulo da. Estudos de Direito Constitucional em homenagem a José Afonso da Silva. São Paulo: Malheiros, 2003, p. 231-243.
} 
A principal justificativa desse fenômeno recai sobre a consagração das conhecidas sociedades pluralistas, que, na concepção de LUIZ FERNANDO COELHO $^{46}$, são caracterizadas pela coexistência de diversos sistemas jurídicos no mesmo espaço social, afastando-se a ideia de um poder soberano e, consequentemente, de qualquer teoria monista do Estado e do Direito.

Situando no espaço o referencial de sua Teoria Crítica do Direito - constituído, por um lado, pela sociedade em que vivemos e, por outro, pelo direito positivo delimitado pela dogmática jurídica - $\mathrm{COELHO}^{47}$ ilustra a ideia dessa concorrência de ideais na atualidade afirmado que "a realidade social apresenta-se como o espaço dos conflitos, em cujo contexto se engendra e promove a ação libertadora dos grupos oprimidos, revelandose a sociedade real como a dialética da dominação, cujo produto é a alienação, e da libertação, cujo corolário é a conscientização".

Para prevenir a ocorrência dos chamados conflitos intersubjetivos de interesses, nos lembra WILLIS SANTIAGO GUERRA FILHO que se torna imperioso o desenvolvimento de um conjunto de normas vinculativas primárias (de $1^{\circ}$ grau), permanentes ou transitórias, visando garantir a necessária convivência dos membros de um grupo social e regulamentando a distribuição dos bens de forma que se não satisfaça plenamente as necessidades, ao menos mantenha os conflitos dentro de um limite tolerável. Nesse contexto, chega-se à localização das normas de direito material ao lado das normas de direito processual. ${ }^{48}$

Ocorre que nem sempre essa relação entre direito material e direito processual envolvidos em uma lide é o bastante para se promover a total prevenção ou, em nível mais avançado, a repressão dessa situação de antagonismo, sobretudo quando os valores em jogo sejam de hierarquia constitucional - incluindo os direitos fundamentais. Para isso, o aplicador do direito deve ir além, fundando-se em juízos valorativos de sopesamento, em conformidade com o caso concreto.

Esse mesmo fenômeno é também constatado por GUERRA FILHO ${ }^{49}$ :

Dentre os resultados alcançados por mencionados estudos pode-se destacar, de antemão que, de um modo geral, se nega a possibilidade de se vir a estabelecer um sistema metodológico de diretrizes, capaz de levar a conclusões de acerto indubitável sobre cada caso. Não importa que hajam

BORNHOLDT, Rodrigo Meyer. Métodos para resolução do conflito entre direitos fundamentais. São Paulo: RT, 2005.

${ }^{46}$ COELHO, Luiz Fernando. Teoria crítica do Direito. 3 ed. Belo Horizonte: Del Rey, 2003, p. 426.

${ }^{47}$ COELHO, Luiz Fernando. Op. cit., p. 573.

${ }^{48}$ GUERRA FILHO, Willis Santiago. Notas sobre a fenomenologia do processo. Revista de Processo, $\mathrm{n}$. 61, São Paulo: RT, 1991, p. 285. Aliás, nesse contexto, é perfeitamente justificável o fenômeno da constitucionalização do processo conforme vem defendendo autores do peso de LÊNIO LUIZ STRECK (Hermenêutica jurídica em crise: uma exploração hermenêutica da construção do Direito. 2 ed. Porto Alegre: Livraria do Advogado, 2000, p. 234-235), PETER HÄBERLE (O recurso de amparo no sistema germânico de Justiça Constitucional. Direito Público n. 2, Porto Alegre: Síntese, 2003, p. 98) além do próprio WILLIS SANTIAGO GUERRA FILHO (Teoria processual da Constituição. São Paulo: Celso Bastos Editor, 2002, p. 27-28. V. também, de Guerra Filho: Quadro teórico referencial para o estudo dos direitos humanos e dos direitos fundamentais em face do direito processual. Revista de Ciências Jurídicas e Sociais da UNIPAR, vol. 5, Toledo: Unipar, 2002, p. 265). Não é demais lembrar que o art. $1^{\circ}$ do $\mathrm{CPC} / 2015$ levou a cabo tal ideia, referindo-se expressamente às normas de cariz constitucional sobre processo como a base e o substrato da própria ciência processual.

${ }^{49}$ GUERRA FILHO, Willis Santiago. Metodologia jurídica e interpretação constitucional. Revista de Processo, n. 62, São Paulo: RT, 1991, p. 126 
várias posições, igualmente fundamentadas, sobre o mesmo caso, contanto que a argumentação forneça também os critérios adotados, a fim de que se possa avaliar sua razoabilidade.

Essa variedade de posições decorrentes da pluralidade de valorações possíveis, o que nos leva a outra constatação fundamental: a necessidade de sopesar princípios, além da mera subsunção de fatos a normas, partes do ordenamento jurídico, especialmente quando se trata de fazer uma interpretação "à luz da Constituição", ou da própria Constituição, que é o texto normativo onde tais princípios naturalmente se localizam.

Essa necessária concorrência entre direitos fundamentais já vinha sendo destacada por NORBERTO BOBBIO ao justificar a inexistência de um fundamento absoluto para os denominados "direitos do homem". Assim, já dizia o filósofo italiano que "deve-se falar de direitos fundamentais não absolutos, mas relativos, no sentido de que a tutela deles encontra, em certo ponto, um limite insuperável na tutela de um direito igualmente fundamental, mas concorrente" ${ }^{, 50}$.

Encontra-se na doutrina uma distinção entre os limites imanentes e as colisões de direitos fundamentais. Estas se caracterizam pelo conflito in concreto de direitos. Aqueles, por sua vez, são construções dogmáticas para explicar e justificar a possibilidade de delimitação ou restrição de determinado direito fundamental, resumindo-se a um problema de delimitação ou de ponderação ${ }^{51}$.

Ainda assim, é inegável o fato de que, em geral, os limites imanentes nascem a partir de uma situação de colisão de direitos fundamentais. Nesse ponto, afastam-se de plano os chamados conflitos aparentes de direitos fundamentais, para que o foco recaia sobre aqueles que podem realmente ser considerados hard cases.

Uma típica colisão de direitos fundamentais necessariamente envolve o choque entre dois preceitos constitucionais. Assim, cogita-se uma colisão entre o exercício de dois direitos fundamentais propriamente ditos, ou ainda, uma colisão entre o exercício de um direito fundamental e outros valores constitucionalmente protegidos ${ }^{52}$.

Já as colisões aparentes, conforme afirma GILMAR MENDES ${ }^{53}$, dão-se quando a conduta questionada já se encontra fora do âmbito de proteção dos direitos fundamentais. Nesses casos, seguindo VIEIRA DE ANDRADE ${ }^{54}$, é o próprio preceito constitucional que não protege a forma de exercício do direito fundamental supostamente em choque, ou melhor, é a própria Constituição que, ao enunciar seu conteúdo, exclui do respectivo programa normativo a proteção desse tipo de situação.

Um exemplo dessa situação de aparência pode ser visto em julgado em que o Tribunal Constitucional alemão afirmou que o direito de manifestação do pensamento

\footnotetext{
${ }^{50}$ BOBBIO, Norberto. A era dos direitos. Rio de Janeiro: Campus, 1992, p. 42.

${ }^{51}$ STEINMETZ, Wilson Antônio. Colisão de direitos fundamentais e princípio da proporcionalidade. Porto Alegre: Livraria do Advogado, 2001, p. 63.

52 CANOTILHO, José Joaquim Gomes. Op. cit., p. 1.270. FARIAS, Edilsom Pereira de. Colisão de direitos: a honra, a intimidade, a vida privada e a imagem versus a liberdade de expressão e informação. Porto Alegre: Sérgio Antônio Fabris Editor, 1996, p. 93.

${ }^{53}$ MENDES, Gilmar Ferreira. Op. cit., p. 77.

${ }^{54}$ ANDRADE, José Carlos Vieira de. Op. cit., p. 295.
} 
não autoriza o inquilino a colocar propaganda eleitoral na residência do senhorio (BVerfGE 7, 230, 234 e s.) ${ }^{55}$.

Seguindo essa linha, não seria possível invocar a liberdade religiosa para efetuar sacrifícios humanos ou, associada ao direito de contrair casamento, para justificar a poligamia, ou ainda invocar a liberdade artística para legitimar a morte de um ator no palco etc.

Em todas essas situações, vê-se que o núcleo fático representado em uma suposta colisão de direitos fundamentais não é protegido pelo conteúdo material desse direito, afastando-se, por consequência, a ideia de ponderação.

A partir daí, com apoio em VIEIRA DE ANDRADE ${ }^{56}$, pode-se afirmar que há limites imanentes nos direitos fundamentais "sempre que (e apenas quando) se possa afirmar, com segurança e em termos absolutos, que não é pensável, em caso algum, que a Constituição, ao proteger especificamente um certo bem através da concessão e garantia de um direito, possa estar a dar cobertura a determinadas situações ou formas do seu exercício; sempre que, pelo contrário, deva concluir-se que a Constituição as exclui sem condições nem reservas".

Seguindo sistematização de ROBERT ALEXY ${ }^{57}$, as colisões de direitos fundamentais são de sentido estrito ou de sentido amplo. São colisões em sentido estrito os choques somente entre direitos fundamentais. Já as colisões em sentido amplo envolvem direitos fundamentais e outros princípios ou valores que tenham por objeto o bem comum.

Há ainda algumas subdivisões.

As colisões de direitos fundamentais em sentido estrito se desdobram em duas possibilidades: (i) colisões entre direitos fundamentais idênticos e (ii) colisões entre direitos fundamentais diversos.

Tratando das colisões de direitos fundamentais idênticos, quatro situações podem ser imaginadas: (i) colisão de direito fundamental enquanto direito liberal de defesa; (ii) colisão de direito de defesa de caráter liberal e o direito de proteção; (iii) colisão do caráter negativo de um direito com o caráter positivo desse mesmo direito; e (iv) colisão entre um aspecto jurídico de um direito fundamental e o seu aspecto fático. ${ }^{58}$

\footnotetext{
${ }^{55}$ Citado por MENDES, Gilmar Ferreira. Op. cit., p. 78.

${ }^{56}$ ANDRADE, José Carlos Vieira de. Op. cit., p. 295.

57 ALEXY, Robert. Colisão e ponderação como problema fundamental da dogmática dos direitos fundamentais. Ed. mimeografada e traduzida por Gilmar Mendes da palestra proferida na Fundação Casa de Rui Barbosa, Rio de Janeiro, em 10.12.1998, p. 1.

${ }^{58}$ No Brasil, MARINONI, versando sobre esse último caso, aponta que os juizados especiais foram criados com o intuito de atender a população carente: "um ordenamento jurídico que se funda no princípio da dignidade humana e objetiva tratar as desigualdades deve formatar o Poder judiciário de modo a atender aos mais pobres, pena de deixa-los à margem da legalidade e entregues às relações de força, o que certamente conduziria a uma perigosa desestabilização social. [...] A filosofia dos juizados é tocada pelo tema da demora do processo apenas porque o hipossuficiente é aquele que mais sofre com o retardo na entrega da prestação jurisdicional. [...] A ideologia dos juizados requer a instituição de uma mentalidade voltada para o trato das questões das pessoas carentes." (MARINONI, Luiz Guilherme. Técnica processual e tutela dos direitos. São Paulo: RT, 2004, p. 103-105.
} 
Quanto a colisão de direitos fundamentais diversos, ALEXY $^{59}$ chama a atenção para o tema tratado por EDILSOM PEREIRA DE FARIAS ${ }^{60}$, ou seja, o conflito entre a liberdade de opinião, de imprensa ou liberdade artística, de um lado, e o direito à honra, à privacidade e à intimidade do outro lado.

\section{CONCLUSÕES}

As restrições de direitos fundamentais nascem a partir da estrutura das normas que os resguardem - mandamentos de otimização - e se afastam das chamadas conformações desses direitos.

No primeiro caso, seja através das restrições vindas da própria Constituição (restrições imediatas), é possível determinar explicitamente uma redução do conteúdo protegido.

No segundo, a própria Constituição pressupõe a atuação do legislador para conformar determinados direitos fundamentais diante de conceitos jurídicos indeterminados.

Em todas as hipóteses de restrições ou conformações de direitos fundamentais, deve-se obrigatoriamente resguardar o chamado núcleo essencial, considerado um conteúdo inatingível e inerente a todos aqueles direitos.

As colisões de direitos fundamentais se dão entre dois direitos propriamente ditos, ou ainda entre um direito fundamental e outro bem - que não revelado em forma de princípio - constitucionalmente protegido. Para sua configuração, porém, deve-se excluir qualquer preceito não resguardado pelo texto constitucional.

\section{REFERÊNCIAS}

ANDRADE, José Carlos Vieira de. Os direitos fundamentais na Constituição portuguesa de 1976. 4 ed. Coimbra: Almedina, 2004.

ALEXY, Robert. Teoría de los derechos fundamentales. Madri: Centro de Estudios Constitucionales, 2002.

Colisão e ponderação como problema fundamental da dogmática dos direitos fundamentais. Ed. mimeografada e traduzida por Gilmar Mendes da palestra proferida na Fundação Casa de Rui Barbosa, Rio de Janeiro, em 10.12.1998.

BARROS, Suzana de Toledo. O princípio da proporcionalidade e as normas restritivas de direitos fundamentais. 3 ed. Brasília: Brasília Jurídica, 2003.

\footnotetext{
59 ALEXY, Robert. Colisão e ponderação como problema fundamental da dogmática dos direitos fundamentais. Ed. mimeografada e traduzida por Gilmar Mendes da palestra proferida na Fundação Casa de Rui Barbosa, Rio de Janeiro, em 10.12.1998, p. 9.

${ }^{60}$ FARIAS, Edilsom Pereira de. Op. cit. Sobre o tema, v. ainda BARROSO, Luis Roberto. Colisão entre liberdade de expressão e direitos da personalidade. Critério de ponderação. Interpretação constitucionalmente adequada do Código Civil e da Lei de Imprensa. IN: TAVARES, André Ramos. MENDES, Gilmar Ferreira. MARGINS, Ives Gandra da Silva. Lições de Direito Constitucional em homenagem ao jurista Celso Bastos. São Paulo: Saraiva, 2005, p. 324-365.
} 
BARROSO, Luis Roberto. Colisão entre liberdade de expressão e direitos da personalidade. Critério de ponderação. Interpretação constitucionalmente adequada do Código Civil e da Lei de Imprensa. In: TAVARES, André Ramos. MENDES, Gilmar Ferreira. MARGINS, Ives Gandra da Silva. Lições de Direito Constitucional em homenagem ao jurista Celso Bastos. São Paulo: Saraiva, 2005.

BIAGI, Cláudia Perotto. A garantia do conteúdo essencial dos direitos fundamentais na jurisprudência constitucional brasileira. Porto Alegre: Sérgio Fabris Editor, 2005.

BOBBIO, Norberto. A era dos direitos. Rio de Janeiro: Campus, 1992.

BORNHOLDT, Rodrigo Meyer. Métodos para resolução do conflito entre direitos fundamentais. São Paulo: RT, 2005.

CAMAZANO, Joaquín Brage. Los limites a los derechos fundamentales. Madri: Dykinson, 2004.

CANOTILHO, José Joaquim Gomes. Direito constitucional e teoria da Constituição. 7 ed. Coimbra: Almedina, 2003.

CLÈVE, Clémerson Merlin. FREIRE, Alexandre Reis Siqueira. Algumas notas sobre colisão de direitos fundamentais. In: GRAU, Eros Roberto. CUNHA, Sérgio Sérvulo da. Estudos de Direito Constitucional em homenagem a José Afonso da Silva. São Paulo: Malheiros, 2003.

COELHO, Luiz Fernando. Teoria crítica do Direito. 3 ed. Belo Horizonte: Del Rey, 2003.

FARIAS, Edilsom Pereira de. Colisão de direitos: a honra, a intimidade, a vida privada e a imagem versus a liberdade de expressão e informação. Porto Alegre: Sérgio Antônio Fabris Editor, 1996.

GUERRA FILHO, Willis Santiago. Notas sobre a fenomenologia do processo. Revista de Processo, n. 61, São Paulo: RT, 1991.

. Teoria processual da Constituição. São Paulo: Celso Bastos Editor, 2002.

Quadro teórico referencial para o estudo dos direitos humanos e dos direitos fundamentais em face do direito processual. Revista de Ciências Jurídicas e Sociais da UNIPAR, vol. 5, Toledo: Unipar, 2002.

. Metodologia jurídica e interpretação constitucional. Revista de Processo, n. 62, São Paulo: RT, 1991.

HÄBERLE, Peter. Elementos de direito constitucional da República Federal da Alemanha. Porto Alegre: Sérgio Antônio Fabris Editor, 1998.

O recurso de amparo no sistema germânico de Justiça Constitucional. Direito Público n. 2, Porto Alegre: Síntese, 2003.

La garantia del contenido esencial de los derechos fundamentales. Madrid: Dykinson, 2003.

HESSE, Konrad. Elementos de direito constitucional da República Federal da Alemanha. Porto Alegre: Sérgio Antônio Fabris Editor, 1998.

MARINONI, Luiz Guilherme. Técnica processual e tutela dos direitos. São Paulo: RT, 2004.

MENDES, Gilmar Ferreira. Direitos fundamentais e controle de constitucionalidade. 3 ed. São Paulo: Saraiva, 2004. 
MENDES, Gilmar Ferreira; COELHO, Inocêncio Mártires; BRANCO, Paulo Gustavo Gonet. Hermenêutica constitucional e direitos fundamentais. Brasília: Brasília Jurídica, 2002.

MIRANDA, Jorge. Manual de Direito Constitucional. Toma IV, 2 ed. Coimbra: Coimbra Editora, 1997.

MOREIRA, Isaura Roque; ZAMITH, Sonia Maria Agra. Direitos E Garantias Fundamentais E A Consolidação Dos Direitos Sociais Dos Trabalhadores No Estado Contemporâneo. Revista Jurídica, [S.1.], v. 3, n. 40, p. 301 - 321, jan. 2016. ISSN 2316$753 \mathrm{X}$. Disponível

em:

<http://revista.unicuritiba.edu.br/index.php/RevJur/article/view/1362/919>. Acesso em: 23 abr. 2020. doi:http://dx.doi.org/10.21902/revistajur.2316-753X.v3i40.1362.

NOVAIS, Jorge Reis. As restrições aos direitos fundamentais não expressamente autorizados pela Constituição. Coimbra: Coimbra Editora, 2003.

PULIDO, Carlos Bernal. El principio de proporcionalidad y los derechos fundamentales. 2 ed. Madri: Centro de Estudios Políticos y Constitucionales, 2005.

QUEIROZ, Cristina M. M. Direitos fundamentais (teoria geral). Coimbra: Coimbra Editora, 2002.

SANCHIS, Luis Prieto. Justicia constitucional y derechos fundamentales. Madri: Editorial Trotta, 2003.

SCHMITT, Carl. Teoría de la Constitución. Madri: Alianza, 1996.

STEINMETZ, Wilson Antônio. Colisão de direitos fundamentais e princípio da proporcionalidade. Porto Alegre: Livraria do Advogado, 2001.

STRECK, Lênio Luiz. Constituição: limites e perspectivas de revisão. 2 ed. Porto Alegre: Rigel, 1993.

Súmulas no direito brasileiro: eficácia, poder e função - A ilegitimidade constitucional do efeito vinculante. 2 ed. Porto Alegre: Livraria do Advogado, 1998.

Hermenêutica jurídica em crise: uma exploração hermenêutica da construção do Direito. 2 ed. Porto Alegre: Livraria do Advogado, 2000.

VIEIRA DE ANDRADE, José Carlos. Os direitos fundamentais na Constituição portuguesa de 1976. 3 ed. Coimbra: Almedina, 2004.

YOKOHAMA, Alessandro Otavio. Teoria da proporcionalidade: o Judiciário como legislador. Porto: Editorial Juruá, 2018. 